\title{
CANTOS Y CANCIONES EN LA OBRA DE CARPENTIER
}

Entre los varios materiales con que Carpentier enriqueció su obra, figuran cantos y canciones de distinto origen. Por razones obvias, sólo se incorporó la letra. Por razones no tan obvias, la incorporación suele determinar sorpresas. Y cualquiera sea el motivo que la provoque, no puede negarse que, gracias a ella, el autor se proporcionó un agridulce placer y el lector interesado siempre resulta ganancioso.

Según confesión del propio Carpentier, la primeriza y despareja Ecue-Yamba-O (1933) ${ }^{1}$ tuvo por puntos de partida el contacto juvenil del autor con los campesinos cubanos, el entusiasmo que le causaron los estudios de Fernando Ortiz y los hallazgos determinados por atrevidas búsquedas, especialmente entre los ñáñigos de Regla ${ }^{2}$. Por propia confesión, también, nos enteramos de que en la novela intentaba pintar la vida de los negros de la clase rural de $\mathrm{Cuba}^{3}$, cuyos cantos y danzas eran formas importantes de expresión, aunque terminó por incorporar a los negros de las ciudades. Arrastrado por intereses que manejaría mejor más tarde, Carpentier retrocedió al pasado con la evocación de la Culebra ${ }^{4}$

${ }^{1}$ Se sigue la edición de las Obras completas de ALEjo CARPENTIER, Siglo XXI, México, 1983, t. 1, pp. 21-193. Después de la cita al texto, señalo entre paréntesis el número de páginas; lo mismo se hará para las otras novelas de Carpentier.

2 Cf. "Problemática de la actual novela latinoamericana", Tientos y diferencias, Arca, Montevideo, 1967, p. 14, y "El recuerdo de Amadeo Roldán" (1939) en Crónicas, Instituto Cubano del Libro-Arte y Literatura, La Habana, 1976 , t. 2, pp. 133-134.

${ }^{3}$ Cf. "Problemática...", p. 14. CAR PENTIER juzga también duramente la novela (pp. 14-15). La conciencia de sus defectos, sin embargo, le evitó escollos en el futuro.

${ }^{4}$ Cf. EMMA SUSANA SPERATTI-PIÑERO, "Sobre un texto recurrente en Carpentier", Fil (en prensa). 
y se extendió a Puerto Rico con una de las tantas coplas de una

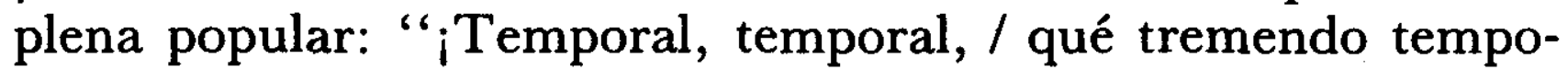
ral! / ¡Cuando veo mi casita, / me dan ganas de lloral!'” (p. 56)5. Siguiendo un impulso de musicólogo incipiente, tampoco se resignó a hablar sólo de los negros, sino que se refirió también a los campesinos blancos:

Varios cantadores guajiros improvisaban décimas[...]. Las flores poéticas nacían sobre monótono balanceo de salmodias quejosas. Las coplas hablaban de trigueñas adoradas a la orilla del mar, del zapateado cubano y de gallos malayos, de cafetales y camisas de listado; todo iluminado con tintes ingenuos, como las litografias de cajas de puros[...].
¡Ese caballo fue mío, valiente caminador!
Era de un gobernador de la provincia del Río (p. 77).

Las ocasiones en que el material se incluye se reducen a tres. Son las reuniones donde el grupo es el personaje principal: la celebración del santo de Eusebio Cué (pp. 47-50), el episodio en la bodega de Canuto (pp. 76-77), la iniciación ñáñiga (pp. 151-158), la Nochebuena en el Centro Espíritu de Cristalina Valdés (pp. 174-175). En ellas se concentran las evocaciones colectivas o individuales que resultan de un estado de ánimo o de un comentario: el descontento de los cosechadores de caña: "Yo no tumbo caña, / ¡que la tumbe el viento! / ¡O que la tumben las mujeres / con su movimiento!" (p. 49); el temor a la muerte que acongoja a Eusebio mientras vaga extraviado la noche del huracán: "Lo bailarían, / lo bailarían, / que sí, / que no. / Lo bailarían, / y se acabó" (p. 60); el convencimiento revelado en el delirio de Menegildo de que la brujería de un haitiano lo ha herido y le ha quitado a la mujer que quiere: "Pobre Candita la loca, / que Lucumí la mató. / Ella me daba la ropa, / ella me daba de tó" (p. 106); la necesidad de dirigirse al pueblo con "alimento ideológico" y "una doctrina concreta", como "El Mayoral se va, / se va, se va, se va. / Ahí viene el chino Zayas / con la Liga Nacio-

${ }^{5}$ La plena fue grabada por mi exalumna puertorriqueña Lili Gómez y el coro de las Wheatones en In the Mood (Wheaton College, Massachusetts, 1978, cara 1, canción 6). Desgraciadamente la copla citada por Carpentier no figura entre las que aparecen en el disco. 
nal' (p. 113); la intervención repentina del autor, quien, mal disimulado por el pensamiento de un personaje, trae a cuento algo que éste posiblemente desconocía (p. 56).

En casi todos los casos, Carpentier trata de suplir la imposible transcripción de la música con descripciones interpretativas:

El son comenzó a pasar de la afinación al canto. Después de vibrar en frío, los percutores sonaban con más vigor. Cundió un hai-kai tropicalísimo:

Son de Oriente,
son caliente,
mi son de Oriente.

$\mathrm{Y}$ todas las voces partieron sobre un mismo ritmo. Las claves se entrechocaban en tres largas y dos breves. Los sonidos se subían a la cabeza como un licor artero (p. 174).

En Ecue-Yamba-O, pues, a pesar del propósito inicial, Carpentier, entusiasmado con sus materiales, se empeñó en abarcar demasiado y realizó un esfuerzo de acumulación que la impericia le impidió dominar convenientemente. Pasaría mucho tiempo antes de que, con criterio más selectivo y mejor técnica, regresara a la incorporación de canciones en el campo de la novela.

Durante sus años de exilio, Carpentier escribió sobre todo artículos. Muchos fueron comentarios sobre música. Varios, sin serlo, se refirieron a canciones oídas y a veces incluyeron la letra, como ocurre en la serie España bajo las bombas ${ }^{6}$. Algunas de las canciones recogidas entonces reaparecerían en el futuro, como ocurrió con una de Ecue-Yamba-O y con otra de La música en Cuba (1946).

Sabemos que Carpentier se interesó por las culturas negras de América y por la huella que imprimieron en nuestros países; que su interés le había proporcionado ya información suficiente como para producir en Francia un documental cinematográfico sobre el vudú, a principios de la década del 30; que en 1943 viajó a Haití, donde estuvo alrededor de una semana y presenció lo que hoy llamaríamos espectáculos especialmente organizados. Sabe-

${ }^{6}$ Los cuatro artículos que forman la serie se publicaron inicialmente en la revista Carteles de La Habana. De ellos interesan especialmente los tres últimos (26 de septiembre, 10 y 31 de octubre de 1937). Los compiló Julio Rodríguez-Puértolas en ALEJO CARPENTIER, Bajo el signo de la Cibeles, Nuestra Cultura, Madrid, 1979, pp. 144-176. 
mos también que el mismo año se le encargó la preparación de La música en Cuba. Ésta le exigió una serie de lecturas y relecturas vinculadas con todo lo anterior, puesto que, a pesar del título, el libro quería abarcar otras zonas del Caribe cuyo contacto hubiera determinado influencias. Sabemos, por fin, que esas lecturas y relecturas, sumadas a una nueva y copiosa bibliografía, iban a contribuir a la composición de $E l$ reino de este mundo $(1949)^{7}$, pensado más o menos al mismo tiempo que el trabajo de investigación ${ }^{8}$. Y en la nueva novela también aparecen canciones, esta vez fundamentalmente relacionadas con una teoría expuesta en el prólogo9. De acuerdo con ella, "la sensación de lo maravilloso presupone una fe" (p. 109). Esa fe la inspiraron a sus seguidores caudillos-mesías como Mackandal a través del vudú $^{10}$. Nada tiene de raro, pues, que los seis cantos afrohaitianos que se integran en la novela sean rituales o de origen ritual ${ }^{11}$. Frente a esto debe permitírsenos un comentario pertinente: si seis es prácticamente la cantidad total de canciones en $E l$ reino, seis es el número de las que aparecen en un breve pasaje de Ecue-Yamba$O$ (pp. 47-50). De la comparación resulta claro que Carpentier había decidido sacrificar la cantidad y la diversidad en favor de la unidad de intención y de sentido.

Danzas-cantos rituales acompañados por tambores fueron "elements which all slaves in Haiti... had in common" 12 , aunque es difícil que los de entonces llegaran hasta nosotros ${ }^{13}$, pese a sus fuertes raíces religioso-tradicionales. Carpentier, que había leído a fondo la obra de Price-Mars, debió de saberlo bien. El conte-

7 Alejo CARPENTIER, Obras completas, t. 2, pp. 9-119.

${ }^{8} \mathrm{Cf}$. EMma SuSANA SPERATTI-PIÑERO, Pasos hallados en "El reino de este mundo", El Colegio de México, México, 1981.

${ }^{9}$ Dicho prólogo sólo figura en las primeras ediciones mexicanas. Luego se incorporó ligeramente modificado al final de "De lo real maravilloso americano", Tientos y diferencias, pp. 107 ss.

10 Cf. J[EAN] PRICE-MARS, Ainsi parla l'oncle... Éssais d'ethnographie, Compiègne, 1928, p. 49.

${ }^{11}$ A los seis cantos afrohaitianos debe agregarse una canción de origen puramente europeo: "Sous ses lois l'amour veut qu'on jouisse / d'un bonheur qui jamais ne finisse!" (p. 60). La aparente excepción queda plenamente justificada, cuando se advierte que sirve para subrayar el derrumbe moral de las emigradas francesas en Cuba.

12 Melville J. Herskovits, Life in a Haitian Valley, Alfred A. Knopf, New York-London, 1937, p. 24.

13 “'Je ne crois pas qu'il soit parvenu jusqu'à nous une seule des chansons qui durent apaiser la cruauté des heures de la servitude coloniale" (PRICEMARS, op. cit., p. 20). 
nido de Haiti Singing ${ }^{14}$, sin embargo, le impuso una irresistible tentación. Como resultado, canciones relativamente recientes pasaron a El reino, cuya acción ocurre más o menos entre 1750 y 1830. Las dos primeras muestran la exaltación de los esclavos antes y después de la repentina reaparición de Mackandal durante la Nochebuena de 1757 (pp. 39-40). De la casi secular danza con$\mathrm{ga}^{15}$ "Roulé, roulé, Congoa roulé"'16 se pasa al estallido de un yanvalú ritual del grupo Radá17. Éste ofrece, por un lado, la ventaja de no precisar la divinidad invocada, con lo que se le hace sugerir una etapa temprana de la evolución del vudú; por otra parte, su introducción en un contexto donde nada revela su valor de acción de gracias concentra la atención en su característica de plegaria suplicante ${ }^{18}$ :

...de pronto, sin previo acuerdo, todas las voces se unieron en un yanvalú solemnemente aullado sobre la percusión. Al cabo de una espera de cuatro años, el canto se hacía cuadro de infinitas miserias:

Yenvalo moin Papa! ${ }^{19}$

Moin pas mangé qu'm bambo

Yanvalou, Papa, yanvalou moin!

Ou vlai moin lavé chaudier

Yenvalo moin?20

...como salidas de las entrañàs, las interrogaciones se apretaban cobrando, en coro, el desgarrado gemir de los pueblos llevados al exilio (p. 40) ${ }^{21}$.

${ }^{14}$ Harold Courlander, Haiti Singing (1939), Cooper Square Publishers, New York, 1973.

${ }^{15}$ Vale la pena recordar que "il serait arbitraire de segmenter la musique, la danse et le chant: ils forment un tout" (JACQUES ROUMAIN, Le sacrifice du tambour assotor, Port-au-Prince, 1943, p. 21).

${ }^{16} \mathrm{H}$. COURLANDER, op. cit., p. 157 y melodía 102.

${ }^{17}$ Cf. ibid., p. 102 y ROUMAIN, op. cit., p. 21.

${ }^{18}$ Cf. Katherine Dunham, Island Possessed, Doubleday, Garden City, 1969 , p. 135; HeRSKOVITS, op. cit., p. 263; LOUIS MAXIMILIEN, Le Vodou Haïtien. Rites Radas-Canzo, Imprimerie de l'État, Port-au-Prince, 1945, p. 33; ROUMAIN, op. cit., p. 21.

${ }^{19}$ Las divinidades del vudú "constituent un Olympe innombrable... dont les plus grandes... portent le titre de Papa ou Grand Maître" (PRICE-MARS, op. cit., p. 32).

20 Aunque con alteraciones de puntuación y tres variantes de la palabra yanvalú, se toma de COURLANDER, op. cit., p. 105, quien para este caso no recoge la melodía.

${ }^{21}$ Es posible que el pasaje citado se inspire en otro de EMILIO BACARDí MOREAU (Vía Crucis, Primera parte: Páginas de ayer, 1910; reimpreso por Ama- 
Otras dos canciones aparecen también en una situación culminante: la recreación de la noche en Bois Caiman:

Junto a Bouckman, una negra huesuda, de largos miembros, estaba haciendo molinetes con un machete ritual.

Fai Ogun, Fai Ogun, Fai Ogun, oh! Damballah m'ap tiré canon!

Fai Ogun, Fai Ogun, Fai Ogun, oh! Damballah m'ap tiré canon!

Ogún de los hierros, Ogún el guerrero, Ogún de las fraguas, Ogún mariscal, Ogún de las lanzas, Ogún-Changó, OgúnKankanikán, Ogún-Batalá, Ogún-Panamá, Ogún-Bakulé, eran ahora invocados por la sacerdotisa del Radá, en medio de la grita de sombras:

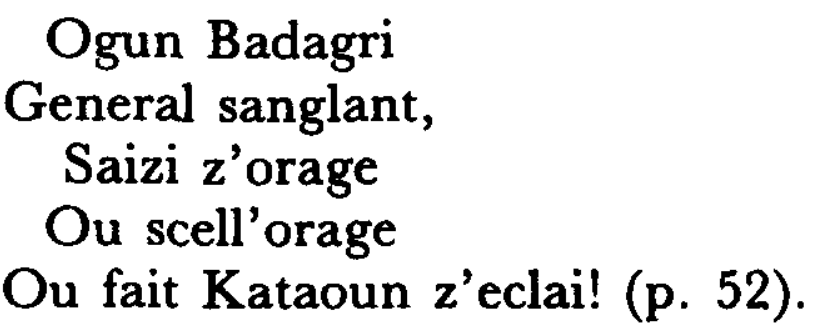

De acuerdo con Bellegarde, la célebre noche del pacto, "une négresse d'une taille gigantesque, jusque-là inaperçue, fit brusquement son apparition... elle entonna un chant africain qui fut répété en choeur' 22 . Carpentier enriqueció la desnuda narración con lo que parece también un solo y largo canto dividido en tres partes. Éste es, en realidad, una suma de materiales con un solo rasgo común: invocar una divinidad haitiana cuyas diversas manifestaciones se vinculan con la guerra ${ }^{23}$. La primera parte transcribe un canto Radá donde, según Courlander, Ogún "plays with a cannon and teases Damballah Wédo"'24. ¿Habría esto sugerido a Carpentier que la desavenencia entre el poderoso pero esencial-

lia Bacardí en los Estados Unidos en 1970, sin indicación ni de editorial ni lugar, pp. 56-57). Pero fuera de la arquitectura general y un lamento-protesta en créole, las diferencias son más que las semejanzas.

22 Windsor Bellegarde, Petite histoire d'Haïti (1492-1915), Port-auPrince, 1929, pp. 48-49.

${ }^{23}$ COURLANDER. op. cit., pp. 40, 79 y 438-439; HERSKOVITS. op. cit., pp. 316-317.

${ }^{24}$ COURLANDER, op. cit., p. 79 y melodía 6 . 
mente benigno Damballah y el agresivo Ogún se prestaba para mostrar una oscilación en el sentimiento religioso haitiano, oscilación que le convino trasladar a 1791? ¿Sería esto lo que le hizo colocar el texto en posición inicial y luego progresivamente atribuir cada vez más importancia al dios de la guerra? Es muy posible. La segunda parte del canto es una verdadera letanía. Inspirada formalmente tanto por Roumain ${ }^{25}$ como por Maximilien ${ }^{26}$, a ella se incorpora una serie de anacrónicos Ogunes, cuyos nombres abren una visión del futuro. La tercera parte, por fin, cita un texto registrado por Seabrook ${ }^{27}$ y cierra con un clímax la invocación comenzada con los jugueteos bélicos de Ogún.

Si los cuatro cantos anteriores son interpretados por grupos, los dos restantes se colocan en el pensamiento o en los labios de personajes individuales. De ambos, uno muestra por asociación que en Ti Noel no se habían agotado ni el impulso combativo ni la fe que lo hizo surgir. Así, la meditación frente a los santos católicos en la catedral de Santiago de Cuba, le recuerda simultáneamente que Ogún Fai fue el dios "a cuyo conjuro se habían alzado los hombres de Bouckman" y que es también Santiago el Mayor ${ }^{28}$. Ya en trance de evocaciones, retrocede aún más en el tiempo: "Ti Noel, a modo de oración, le recitaba a menudo un viejo canto oído a Mackandal: "Santiago, soy hijo de la guerra: / Santiago, / ¿no ves que soy hijo de la guerra?"' (p. 62). El texto no sólo es el único en la novela en que se abandona el créole por el español, sino que está lejos de ser una traducción precisa ${ }^{29}$. Por otra parte, constituye el caso más evidente de anacronismo voluntario, puesto que, según Courlander, "it is a song known at least as early as the middle of the nineteenth century" 30 , claramente un siglo después de la relación magistral de Mackandal con Ti Noel. El último canto utilizado por Carpentier en $E l$ reino de este mundo lo lloriquea Solimán durante su enfermedad en Roma. Se vale de él para atraer la atención de un dios vengativo y colérico pero capaz de apiadarse de un transgresor arrepentido ${ }^{31}$ :

25 Op. cit., pp. 13-14.

26 Op. cit., pp. 42-43.

27 W[ILliaM] B. SEABROOK, The Magic Island, Harcourt, Brace and Company, New York, 1929, p. 74.

${ }^{28}$ COURlander, op. cit., p. 79; ROUMAIN, op. cit., p. 13.

${ }^{29} \mathrm{Cf}$. ' $S t$. Jacques ou voyé dit'm ga'çon la gué! / C'est moin, St. Jacques! / Ou pas wé'm ga'çon la gué?"' (COURLANDER, op. cit., p. 80 y melodía 7).

30 Loc. cit.

31 HersKovits, op. cit., pp. 30-31; PrICE-MARS, op. cit., pp. 101-102 y 152 . 
"Papa Legba, l'ouvri barrié-a pou moin, agó yé32, / Papa Legba, ouvri barrié-a pou moin, pou moin passé" (p. 110). Del texto consultado ${ }^{33}$, Carpentier seleccionó los dos versos del comienzo, con los cuales concluyó bruscamente el capítulo de "La noche de las estatuas" y las aventuras del en ese momento desesperado Solimán. Final tan abrupto deja al lector muy inseguro sobre el efecto de la breve plegaria. Pero la serie de interrogaciones que se abren ante él de ninguna manera le impide advertir que algo nuevo ha sucedido en relación con los desenlaces parciales de la novela.

Carpentier limitó aún más las intercalaciones en Los pasos perdidos (1953) $)^{34}$, donde sólo hay tres. Dos de ellas se encuentran en el capitulillo correspondiente a la visita que hacen los viajeros a Santiago de los Aguinaldos (pp. 242-247). Allí, el protagonista descubre un ángel que toca maracas entre "las figuras de un concierto celestial" 35 ; asiste a una procesión durante la cual oye un himno religioso " apoyado, en vieja sonoridad de sacabuche y chirimía, por un clarinete y un trombón"; escucha décimas evocadoras de "la historia de unos infantes de Lara desconocida" para él. Más tarde se pregunta "si el papel de estas tierras [las de América] en la historia humana no sería el de hacer posibles, por vez primera, ciertas simbiosis culturales". Lo distrae de su meditación algo que le "sonaba a cosa a la vez muy próxima y muy lejana". Ese algo son los versos de un canto gregoriano salmodiados demasiado oportunamente por fray Pedro de Henestrosa y con los cuales se responde a las consideraciones del protagonista.

Un nuevo matiz de explicación no directamente expresada se ofrece con el fragmento de romance incorporado casi inmediatamente después de la aparición del leproso:

Horrorizado por la idea de que... pueda regresar, invito al hijo del Adelantado a compartir nuestra cena. Presto corre bajo la lluvia a buscar su vieja guitarra de cuatro cuerdas - la misma que sonó a bordo de las carabelas - y sobre un ritmo que hace correr sangre de negros bajo la melodía del romance, empieza a cantar:

32 Según SEABROOK, en la expresión agó-yé, frecuente en los cantos vudúes, agó es una forma verbal que significa 'presta atención', 'escucha', y yé corresponde a las variantes pronominales complementarias (op. cit., p. 291).

${ }^{33}$ ROUMAIN, op. cit., p. 20.

${ }^{34}$ AlEjo CARPENTIER, Obras completas, t. 2, pp. 121-416.

${ }^{35} \mathrm{Para}$ los antecedentes reales del ángel de las maracas y las consideraciones que provocaron en Carpentier, véase "Problemática...", pp. 23-25. 
Soy hijo del rey Mulato

y de la reina Mulatina;

la que conmigo casara

mulata se tornaría (p. 360).

Los versos citados son variante por acomodación de los que sirven a la hija del rey de Francia para horrorizar a un caballero y detener sus requerimientos: "Hija soy de un malato / y de una malatía; / el hombre que a mí llegara / malato se tornaría". El binomio mulato-malato, establecido por la lectura de la variante americana y el recuerdo del romance viejo, más la impresión que en el contexto experimentan los personajes ante el leproso, determina una rápida asociación con dos actitudes discriminatorias. Pero el pasaje no convence totalmente, acaso por ser demasiado melodramático, acaso porque se lo siente excesivamente mecánico en su doble alusión.

El siglo de las luces (1962) ${ }^{36}$ mantiene la parquedad numérica de las incorporaciones, pero se extiende en las oportunidades. Por su sabor patriótico o revolucionario, se asimilan una canción de François Girouet (p. 174) y la variante americana de la Carmañola que se imprime en la Guadalupe con el fin de exportarla "a los pueblos del Nuevo Continente" (p. 195). Y nada tiene de raro que miembros de un pueblo cuyos desacuerdos suelen estallar en violencia sanguinaria, pero cuya expresión popular es el canto, los olviden momentáneamente para satisfacer su natural inclinación:

Era maravilla oír entonces a los españoles concertados en torno al teclado, para contrapuntear la copla:

Cuando Majoma vivía

allá en la era pasada era tanto lo que bebía que del suelo se elevaba con las monas que cogía (pp. 125-126).

El hecho de que sonara en todas las memorias desde un cuarto de siglo atrás (p. 173) quizá explique la presencia del lamento nostálgico compuesto en créole por el marqués de Bouillé, exgobernador de la Guadalupe. Las causas determinantes para la incorporación de los cuatro versos entonados por Ogé - "Dipi mon perdi Lisette / mon pa souchié kalenda; / mon quitté bram-bram son-

${ }^{36}$ Alejo Carpentier, Obras completas, t. 5. 
nette, / mon pa battre bamboula"' (p. 91) - parecen otras. De acuerdo con Moreau de Saint-Méry, iniciaban la tercera estrofa de una canción compuesta unos cuarenta años antes por M. Duvivier de la Mahautière para demostrar la ductilidad del créole ${ }^{37}$, y Carpentier los había utilizado ya en La música de Cuba donde indicaba que las canciones en dialecto habían adquirido "un inesperado acento a la Racan" 38 . En la época a la cual se refieren ambos autores, los enriquecidos descendientes de exesclavos empezaban a asimilar las costumbres y las modas de la sociedad blanca. El Ogé de la novela era uno de ellos, y no sorprende encontrar la canción en sus labios. Cabe preguntarse si volvería a cantarla una vez sabida la muerte de su hermano, ejecutado ferozmente por las autoridades coloniales; la actitud que adopta al despedirse de Esteban y Víctor Hugues en Port-au-Prince (p. 116) sugiere una respuesta negativa.

Novedosa y reveladora es, por fin, la presencia de la canción navideña intercalada durante la fiesta en casa del suegro de Sofía (p. 234). No sólo es el primer ejemplo de villancico que aparece en la obra de Carpentier, sino que descubre un interés o un gusto que hasta entonces se había tenido muy callado.

Siguiendo el modelo establecido por Valle-Inclán en su novela de $1926^{39}$, Carpentier construyó para El recurso del método $(1974)^{40}$ un imaginario país latinoamericano donde se suman circunstancias, hechos y personajes sugeridos por otros, reales, de varias naciones de nuestro continente ${ }^{41}$. Dada esta característica, la obra se prestaba magníficamente para introducir canciones de procedencia diversa. Pero, aunque la tentación debe de haber sido poderosa, Carpentier se limitó prudentemente a unas pocas producciones y sólo a tres países.

México es el más favorecido en cuanto al número. Si la revolucionaria "Adelita" (p. 73) resulta contradictoria en boca de los soldados que van a combatir al rebelde Ataúlfo Galván, no lo

${ }^{37}$ [LOUIS ELIE] MOREAU DE SAINT-MÉRY, Description topographique, civile et historique de la partie française de l'isle Saint-Domingue (1797), éds. Blanche Maurel et Etienne Taillemite, Société de l'Histoire des Colonies Françaises-Librairie Larose, Paris, 1958, t. 1, pp. 81-82.

${ }^{38}$ F.C.E., México, 1972, p. 124.

${ }^{39}$ EMMA SUSANA SPERATTI-PIÑERO, "La elaboración artística en Tirano Banderas", en De "Sonata de otoño" al esperpento, Tamesis Books, London, 1968, pp. 73-239.

${ }^{40}$ Alejo CARPENTIER, Obras completas, t. 6.

${ }^{41}$ Carta de Alejo Carpentier a Arnaldo Orfila Reynal en Cartel Siglo XXI, México, enero-febrero de 1983, núm. 52. 
parece tanto cuando se observa qué versos se han acogido: "Que si Adelita se juese con otro, / la seguiría por tierra y por mar; / si por mar en un buque de guerra; / si por tierra, en un tren melitar'. Y no menos desconcertantes resultan los ligeramente alterados de la también revolucionaria "Valentina", por asociarse con una reflexión del presidente (p. 131). Los sin duda anacrónicos del "Corrido de Rosita Alvírez" proyectan fielmente, en cambio, la actitud semiburlesca que adoptan frente a la violencia quienes los cantan en la novela y quienes lo hacen en el mundo real: "La noche que la mataron / Rosita estaba de suerte. / De seis tiros que le dieron, / no más uno era de muerte"' (p. 55). Y aunque acaso únicamente semi-popular, la copla de protesta con que se anuncia el crecimiento avasallador de la rebeldía provoca innumerables resonancias cuando se la relaciona con el hecho de que había sido muy cantada "en el México de años atrás" (p. 232).

Las tres canciones que pertenecen a la Argentina acentúan con fuerza un rasgo del ya ex. Si bien éste se complace en el destierro con platos regionales y atenúa la nostalgia con la lectura exclusiva de los periódicos de su tierra, cuando canta sigue siendo extranjerizante. Así, junto con fragmentos de lo que suena a letras de valses peruanos, entona insistentemente pasajes de los tangos "Milonguita", "Adiós, muchachos" 42 y "El día que me quieras". En lo que a Cuba se refiere, por fin, Carpentier vuelve a incorporar una copla de protesta que había utilizado en EcueYamba- $\mathrm{O}^{43}$, intercalada ahora en un contexto equivalente al que pudo haberla originado: las huelgas que empiezan a socavar el autoritarismo del hasta entonces todopoderoso presidente (p. 223).

El recurso del método, sin embargo, no se limita territorialmente al sintético país latinoamericano ni lingüísticamente a canciones en español. Una en alemán descubre la recóndita satisfacción del marino internado, para quien han concluido los peligros de la primera guerra mundial (p. 164). El primer verso de "Over there" (p. 165), divulgado a partir de 1917, destaca sarcásticamente los avances del neocolonialismo. "We have no bananas" apunta a la aceptación pasiva de modas extranjeras insignificantes. Ésta, junto con "Titine", recuerda la vulgaridad y la pobreza creadora postbélicas en ciertos medios. Y la paráfrasis de "Mambrú", con

${ }^{42}$ No sé si por error, mala memoria o por algún propósito que se me escapa, Carpentier cambia repetidamente la barra del tango por una farra que nada tiene que hacer en el texto. El mismo fenómeno suele observarse en otras transcripciones, acaso con más escasas posibilidades de explicación.

${ }^{43}$ Cf. pp. 1-3 de este artículo. 
que los amigos de Ofelia despiden al ex, resulta clara señal de la quiebra vertiginosa de algunas costumbres (p. 302).

La consagración de la primavera $(1978)^{44}$ nos depara una sorpresa: todas las canciones se reúnen en un solo capitulillo (13, pp. 145-158), y todas implican una protesta o son abiertamente revolucionarias. Construido a partir de referencias, citas y sugestiones de la serie España bajo las bombas ${ }^{45}$ el capitulillo avanza progresivamente desde los versos iniciales de "Ol'Man River", entonados por el inolvidable Paul Robeson, pasa por los semicoros de las Brigadas Internacionales y culmina con el estallido conjunto del himno revolucionario que sustituyó a la Marsellesa en $1910^{46}$. Y a letras originales como las de la Carmañola y el "Ça ira" se suman creaciones nuevas muy cantadas durante el conflicto con la música de "Los cuatro muleros" y el "Anda, jaleo"'47. El efecto resultante, aunque melodramático, pero quizá por ello, es indudablemente poderoso y en nada contradice lo que la realidad muestra en ocasiones semejantes.

En El arpa y la sombra (1979) ${ }^{48}$ se vuelve a reducir drásticamente el número de canciones. Tres de las cuatro recogidas surgen en las remembranzas de un ya muy viejo Pío Nono, y de las tres, dos son villancicos navideños. El comentario que acompaña a uno de ellos quizá traicione demasiado el gusto personal de Carpentier:

Por las muchachas chilenas conoció algunos de los villancicos que cada año, en Navidades, alegraban la ciudad... Uno, de melodía muy popular, le encantó por su fresca aunque ripiosa candidez:

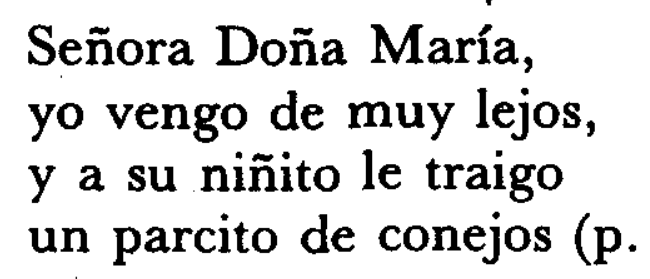

44 Alejo CARPENTIER, Obras completas, t. 7.

${ }^{45}$ Cf. supra, nota 6.

${ }^{46}$ Cf. lo referente a la Internacional en JOAN LLARCH, Cantos y poemas de la Guerra Civil de España, Producciones Editoriales, Barcelona, 1978, pp. 54-55.

47 Cf. CARPENTIER, Bajo el signo de la Cibeles, pp. 155 y 167; LLARCH, op. cit., pp. 72, 77 y 116 .

${ }^{48}$ ALEJO CARPENTIER, Obras completas, t. 4, pp. 215-378.

49 Cf. Eugenio Pereira Salas, Los origenes del arte musical en Chile, 
El otro, o revela un descuido de Carpentier o apunta con un evidente anacronismo del contexto a la senilidad de quien empieza a confundir fechas, acentuando de paso una malévola e insistente asociación:

...el cristalino nombre de Senigallia venía a armonizarse con el muy lejano coro de los esquilones romanos, trayéndole recuerdos de las ruedas... que... bailaban en el transpatio... sus hermanas mayores... todas con voces frescas y alborotosas... cuyo timbre... le hicieron [sic] presentes... aquellas otras voces, también voces niñas, unidas en el villancico ingenuo, escuchado al inicio de unas borrascosas navidades, en la tan distante, tan distante y sin embargo tan recordada ciudad de Santiago de Chile:

Esta noche es Nochebuena y no es noche de dormir, que la Virgen está de parto y a las doce ha de parir (p. 224) ${ }^{50}$.

Imprenta Universitaria, Santiago de Chile, s.a., pp. 192-193. Para mayor comodidad, incorporo el texto y la melodía.

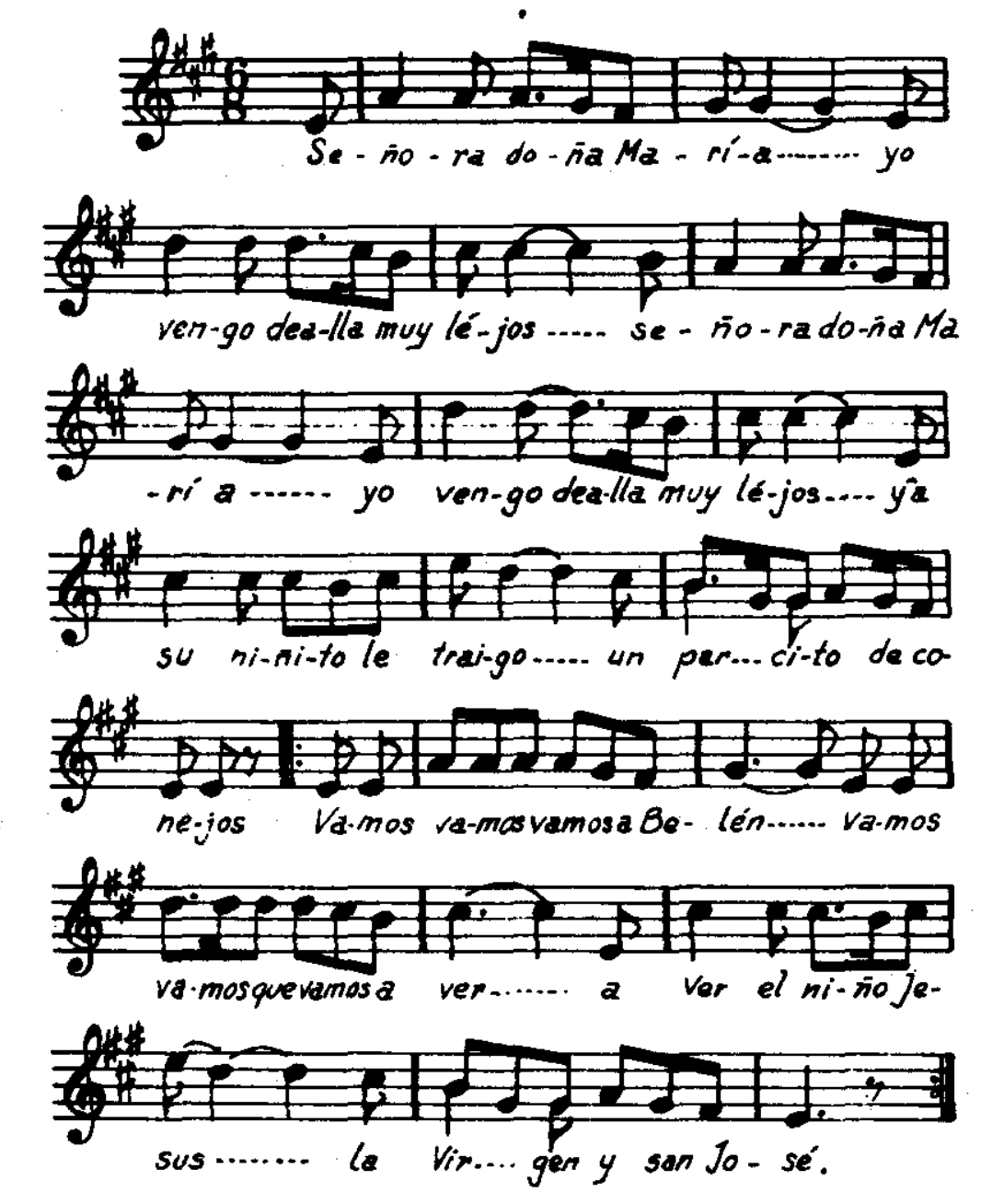

50 Pereira Salas, op. cit., pp. 189-190. 
La misión a la que pertenecía el futuro Papa residió en Chile desde el 5 de marzo de 1824 hasta el 30 de octubre del mismo año, fechas entre las cuales no cabe una Navidad ${ }^{51}$. La tercera canción, la muy conocida “Plaisir d'amour"' del abate Martini (1706-1784), por un lado contribuye a la alusión de que en las relaciones familiares del joven Mastai existió una sensualidad reprimida (pp. 233-234) y por el otro pone de relieve la preocupación del propio Carpentier por los inescrutables caminos de la popularidad y de la fama ${ }^{52}$.

La última intercalación en El arpa y la sombra es la del fragmento "Ea, judíos, a enfardelar"' (p. 266). Éste inicia una copla del siglo XV cuyo final es "que mandan los reyes que paséis la mar"'53. La copla alude claramente al decreto de expulsión (31 de marzo de 1492) y expone el eștado de ánimo general de los españoles del tiempo. Despojada de un final harto preciso, servía para aludir a hechos y actitudes frecuentes desde la ascensión al trono de los Trastamara, hechos y actitudes que habían ido exasperándose con los años para culminar con los ataques a los conversos y con el requerimiento de que se estableciera la Inquisión. Tal recrudecimiento se dejó sentir sobre todo de 1459 a 1482 y provocó el éxodo de muchos judíos y marranos ${ }^{54}$. Éste es el período

${ }^{51}$ Cf. P. Leturia, S.I., "El viaje a América del futuro Pontífice Pío IX, 1823-1825', en Xenia Piana SSmo Dno Nro Pio Papae XII, Librería Herder-Typis Pontificiae Universitatis Gregorianae, Roma, 1943, p. 371, y ALBERTO SERAFINI, Pio Nono, Giovanni Maria Mastai Ferretti, dalla giovinezza alla morte nei suoi scritti e discorsi editi e inediti; t. 1: Le vie della Divina Providenza (1792-1846), Tipografia Poliglota Vaticana, 1958, pp. 288 y 352.

52 Cf. "América Latina en la confluencia de coordenadas históricas y su repercusión en la música", en ALEJO CARPENTIER, La novela latinoamericana en vísperas de un nuevo siglo y otros ensayos, Siglo XXI, México, 1981, p. 163.

53 Cf. Libro sexto, cap. 7, FRANCISCO DE SALINAS, De musica libri septem (Salamanca, 1577), ed. facs., University of Rochester Press, Rochester, NY, 1954, p. 312; FELIPE PEDRELL, "Estudio sobre una fuente de folklore musical castellano del siglo XVI", en Lírica nacionalizada. Estudios sobre folklore musical, Sociedad de Ediciones Literarias y Artísticas-Ollendorf, Paris, s.a., p. 239. Incorporo la transcripción de Pedrell por estar en caracteres musicales modernos.

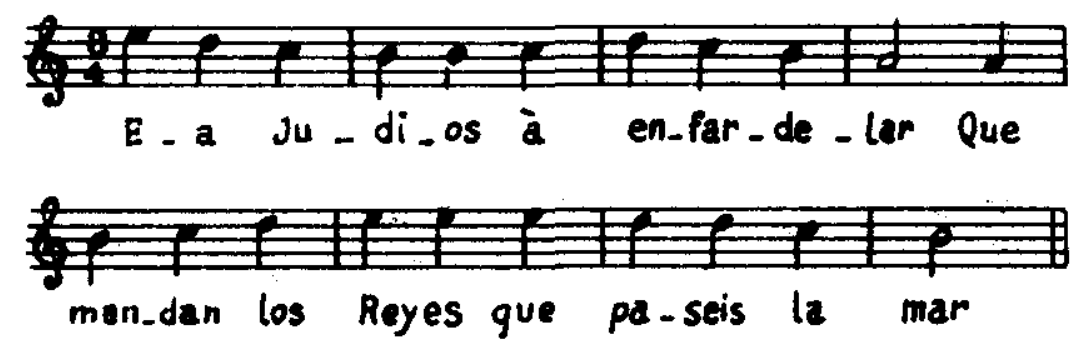

${ }^{54}$ Cf. especialmente el t. 3 de JOSÉ AMADOR DE LOS Rf́os, Historia social, politica y religiosa de los judios de España y Portugal, Madrid, 1876, 3 vols. 
evocado por el maestre Jacobo, cuando cuenta a Colón su vida en Islandia hacia $1477^{55}$, y durante el cual confiesa haber oído la copla (pp. 265-266). Si aquí se comete un flagrante pero útil anacronismo, ninguno hay cuando Isabel anuncia a Colón que le ha arrancado un préstamo a Santángel y lo empuja a "enfardelar" lo suyo para el viaje de descubrimiento (p. 290). Así, la reina, que ya se había servido de los judíos y luego había ordenado su expulsión, sigue explotándolos inescrupulosamente. Además, la Isabel de la novela cohabita de tanto en tanto con el futuro Almirante, a quien Carpentier presenta como criptojudío, pese a que semejante relación estaba expresamente prohibida a las mujeres cristianas $^{56}$. No hay duda de que con sus abusos y transgresiones se ilustran prerrogativas que el autoritarismo se ha atribuido desvergonzadamente desde tiempo inmemorial.

\section{CONCLUSIONES}

Su interés de musicólogo, en ciertos casos una personal predilección y el conocimiento de que cantos y canciones son formas expresivas y reveladoras de quien las crea y de quien las interpreta, determinaron que Carpentier introdujera tantos en su obra. Que el número varíe de novela a novela depende de diversas razones, entre las cuales figuran la impericia que lo llevó al exceso en la etapa inicial de su carrera y el deseo de concentración adecuada más tarde. Aunque con excepciones, la intención de su presencia y la función que desempeñan es generalmente de crítica, sátira o ataque, y para lograr tales propósitos Carpentier no retrocede ante el anacronismo. El efecto que determinen dependerá, naturalmente, de cada lector. Para alguno serán incluso el estímulo que lo empuje a reunir de nuevo las letras con las melodías que las acompañaron. Esto no sólo le hará sentir vívidamente el problema de Carpentier, semiamordazado por la imposibilidad de transcribir íntegramente los cantos y canciones que utilizó, sino que le provocará un profundo agradecimiento por la hermosura de lo que se le ha ayudado a encontrar.

\section{EMMA SUSANA SPERATTI-PIÑERO}

Wheaton College, Massachusetts

${ }^{55}$ Ramón Menéndez Pidal, La lengua de Cristóbal Colón, Espasa-Calpe, Madrid, 1942, p. 16.

${ }^{56}$ Cf. AMADOR DE LOS Ríos, op. cit., t. 3, pp. 301, 400 y 429 n. 